\title{
Symmetry of induced polar states in noncentral crystals under inhomogeneous heating
}

\author{
V.F.Kosorotov, L.V.Shchedrina \\ Institute of Physics, the National Academy of Sciences of the Ukraine, \\ 46 Nauki Ave., UA-252650 Kiev-22, Ukraine
}

Received April 17, 2000

The use of an external vector action in the form of the crystal spatially inhomogeneous heating is advanced as an original and promising method of generating new properties in traditional crystals, which do not possess these properties in the thermodynamically equilibrium state, as an alternative to the universally adopted line - the synthesis of new infrared functional materials. The change of the nature of an external influence or its direction makes it possible to control and vary the crystal polarization properties over a wide range. Tertiary pyroelectric effect is investigated which exhibits the most promising monitoring for an intense IR radiation.

Key words: polar state, tertiary pyroelectric effect, symmetry

PACS: $77.60,77.70$

\section{Introduction}

There are two reasons for our interest in unconventional polar materials for infrared optoelectronics - nonpolar piezoelectrics, which do not belong to pyroelectric classes. First, elaboration of a general approach to the formation of efficient pyroactive media with controlled polarization properties and possessing unique physical characteristics as compared with the true pyroelectrics, is made possible with a rapid research regarding polarization phenomena under nonequilibrium thermal conditions in recent years [1-10]. The second point of our interest consists in developing new technologies in pyroelectric materials and establishing new physical principles for the construction of infrared sensors in a wide spectral range. This can be attributed to the necessity of solving a number of the applied problems involved in registering the superpower and short laser pulses by IR sensors.

A novel approach to the creation of induced pyroelectric media with optimal physical characteristics (as an alternative to the synthesis of new infrared materials) based on the existing nonpolar structures makes it possible to control their polarization properties. New artificial pyroactive structures operate over the crystal 
transparency band and therefore the measurements and monitoring of the output laser radiation are realized without interrupting the technological process. Nonpolar piezoelectrics reveal pyroactive properties under nonequilibrium thermal conditions only. Occurrence of pyroactivity in nonpolar crystals is caused by the presence of the thermoelastic stresses generated as a result of the crystal inhomogeneous heating. Mechanical stresses, in their turn, induce polarization in the crystal through the piezoelectric effect. This mechanism of polarization occurrence is known as a tertiary pyroelectric effect (TPE) [11]. In spite of the active research regarding this effect, a set of phenomena concerned with a crystal polarization under nonequilibrium thermal conditions has not been given a commonly accepted classification up till now.

\section{Symmetry approach under axisymmetric heating}

Spatially inhomogeneous heating of a crystal by incident radiation is advanced as an original and promising method of producing new properties in the traditional crystals which do not exhibit these properties in the thermodynamically equilibrium state. Such a heating refers to external vector effects on the crystal and is described by some point symmetry group $G_{\text {ext }}$. The method idea is reasonably known and consists in the crystal symmetry change in the field of an external applied action. According to the Curie principle, such an effect alters the crystal symmetry group $G$ locally, inducing spatially inhomogeneous polar state in it, since the polar properties of the crystal depend to a large extent on its symmetry. The change character of this symmetry depends not only on a type of the group $G_{\text {ext }}$ but also on a relative spatial orientation of the symmetry elements of groups $G_{\text {ext }}$ and $G_{\text {cry }}\left(G_{\text {cry }}\right.$ is the symmetry group of the unperturbed crystal). The crystal symmetry group in the field of an external perturbation may be put down as follows

$$
G \supseteq G_{\text {cry }} \frown G_{\text {ext }} \text {. }
$$

Therefore, it is apparent that the crystal properties are subject to wide variations under the change of an external action nature or its direction. It should be pointed out that a homogeneous heating likewise is liable to change the crystal symmetry but only under spatially inhomogeneous elastic boundary conditions. A set of these elastic conditions and a homogeneous heating in this situation should be considered as a spatially inhomogeneous effect on the crystal. The potentialities of producing new properties in crystals employing the method mentioned above within the limits of spatially homogeneous external actions have been presently exhausted. To accomplish these ends we pioneered the use of a vector external action in the form of the crystal inhomogeneous heating [12].

The polarization spatial distribution in the plate being rather intricate in structure enables the induced polar states to be used in practice. Derivation of this information involves severe mathematical difficulties. The problem turns out to be solvable due to the analysis of the symmetry properties of the polar states. Advanced symmetry approach proved to be not only an effective method of studying 
the polar state nature but also fruitful in elaborating the physical principles for constructing various pyroelectric devices acting on these induced effects. Symmetry properties of the tertiary pyroelectric effect will be studied for one of the cases frequently realizable in practice i.e. one-dimensional inhomogeneous temperature field, when the temperature in a round plate changes only along its radius. This temperature distribution is realized in the plates subjected to axisymmetric heating by a sine-modulated radiation flux with a wave length in the transparency band of the crystal. It should be noted that TPE symmetry analysis in the plates with temperature varying along the thickness has been previously discussed [13]. This distribution takes place under uniform irradiation of the plate front face by incident sine-modulated radiation flux with a wave length inside the lattice absorption band of the crystal.

Axisymmetric heating creating a temperature radial gradient provides irradiation of the round plate central region by the laser beam with a uniform energy distribution over its section. The temperature field with respect to the variable component involves two zones having a rather uniform temperature distribution within these regions. Transitional layer between zones is very thin (of the order of the temperature wavelength) and may be ignored. On the one hand, this approximation brings about the appearance of the first type discontinuities for the thermoelastic stress tensor at the boundary of regions and hence discontinuity of the polarization vector. On the other hand, the approximation enables the thermal anisotropy to be neglected and the symmetry limiting groups to be introduced.

Under the heating in question, the group of external effect $G_{\text {ext }}$ is variable in location - in the heated region, which is determined by the laser beam radius $r_{o}$, and beyond it

$$
G_{\mathrm{ext}}=\left\{\begin{array}{ll}
\infty / m m m, & r \leqslant r_{o} \\
n / m, & r>r_{o}
\end{array}\right\}
$$

It should be pointed out that the polar state symmetry in the heated region (2) is no different from the one investigated under temperature thickness gradient conditions in [13]. Clearly it derives from the fact that the external effect groups are coincident in both cases.

The symmetry axis $n$ is contained in the group $G_{\text {ext }}$ only if it is present in the crystal symmetry group $G_{\text {cry }}$ and if it is perpendicular to the cut plane $m$. Otherwise, $G_{\text {ext }}=m$. As is seen, the symmetry group of an external effect under thermodynamically nonequilibrium state conditions is spatially inhomogeneous. Generally speaking, the symmetry group $n / m$ is conditional for a nonheated region which is under conditions of a strong spatially inhomogeneous action (i.e., there are loaded internal and mechanically free external surfaces). Notice that if the symmetry axis $n$ and plane $m$ coincident with the normal to the plate and the cut plane, respectively, are absent in the group $G_{\text {cry }}$, the tertiary pyroelectric effect will manifest itself under the dissymmetry conditions. Therefore, in this case the complete numerical calculation of the polar state in a cold region of the plate is requisite for TPE practical applications. 


\section{Symmetry properties of induced polar states}

Let us present for a nonheated region of the crystal the symmetry analysis results of the same crystallographic cuts (studied in [13] under temperature thickness gradient), which are active in relation to the tertiary pyroelectric effect taking into consideration expression (2) and the Curie principle (1). No consideration will be given to the cuts perpendicular to the sole polar direction since the longitudinal TPE must necessarily exist here under heating in question. It makes sense to study these cuts only for a concurrent occurrence of transverse and longitudinal effects.

Monoclinic syngony.

Class $C_{2} . G=I$ ( $I$ is the unit element) in the cuts containing the two-fold axis. TPE manifests itself in these cuts under dissymmetry conditions.

Class $C_{s} . G=I$ in the cuts perpendicular to the directions $\bar{n}\left(n_{1}, 0, n_{3}\right)$ and TPE will occur under dissymmetry conditions.

Rhombic syngony.

Class $D_{2}$. TPE exists in the cuts involving only one of the two-fold symmetry axes under dissymmetry conditions.

Class $C_{2 v} . G=m$ in the cuts normal to the directions $\bar{n}\left(n_{1}, n_{2}, 0\right)$ if only one of the components $n_{i}$ is equal to zero. In these cuts the transverse effect is found. If none of these components become zero, TPE exists under dissymmetry conditions.

Tetragonal syngony.

Classes $C_{4}, S_{4}$. TPE existing under dissymmetry conditions takes place in both classes in the cuts perpendicular to the directions $\bar{n}\left(n_{1}, n_{2}, 0\right)$.

Class $D_{4}$. TPE can manifest itself under dissymmetry conditions in those cuts, a normal to which lies in the plane going through the axis 4 and one of the two-fold axes.

Classes $C_{4 v}, D_{2 d}$. Transverse effect takes place in the cuts coincident with one of the symmetry planes. Longitudinal effect exists in the $D_{2 d}$ class in the cuts perpendicular to the two-fold axes.

Trigonal syngony.

Class $D_{3} . G=2$ in the cuts perpendicular to any one of the two-fold axes and the longitudinal TPE is found. TPE manifests itself in the cuts parallel to these axes under dissymmetry conditions.

Class $C_{3 v} . G=m$ in the cut plane coincident with the symmetry plane and the transverse effect can occur here. TPE is found in the planes perpendicular to the symmetry planes under dissymmetry conditions.

Hexagonal syngony.

Class $C_{6}$. TPE takes place under dissymmetry conditions in all cuts excepting the cut perpendicular to the axis 6 . The latter cut is characterized by availability of a longitudinal effect.

Class $C_{6 v} . G=m$ in all cuts containing the axis 6 . Transverse TPE exists in these cuts. To obtain this result the Hermann theorem should be taken into account.

Class $D_{6}$. This class manifests the same results as the class $D_{4}$. 
Cubic syngony.

Classes $T, T_{d} . G=3(\operatorname{class} T)$ and $G=3 m\left(\operatorname{class} T_{d}\right)$ in the cuts perpendicular to the three-fold axes. In these classes, respectively, longitudinal and transverse effects take place. Longitudinal TPE exists in the cuts perpendicular to the two-fold axes. TPE will occur in the cuts parallel to one of the two-fold axes under dissymmetry conditions.

\section{Some specific features in the behavior of polar states}

Consideration must be given to the conditional character of the results obtained with the use of the Curie principle for the crystals being in thermodynamically nonequilibrium state. A number of new results not filling in the context of the existing knowledge is a consequence of such an approach. This is concerned with the crystallographic cuts the planes of which are perpendicular to the three-fold axes. To take an example, the crystal symmetry groups in the field of an external action $G=3$ and $G=m$ for the crystallographic cuts [111] in a cubic syngony have been obtained. It would seem, the polarization vector is to be directed along the sole polar axis which is contained in these groups. However, the transverse effect is available along with a longitudinal one, and the polarization vector is not coincident with the three-fold axis direction. Furthermore, in analogous cuts of the crystallographic class $D_{3}$, where a longitudinal piezoelectric effect is rigidly forbidden, the polarization vector is perpendicular to the sole polar direction. TPE is completely lacking in the indicated cuts of the crystals possessing the symmetry group $D_{6}$, where $G=6$, in spite of the fact that the sole polar direction is available. This is due to the availability of rotations in the group $C_{6}$ which are not concerned with the three-fold symmetry axis.

Let us deal with the $Z$-cuts of crystals with the symmetry groups $C_{3 h}$ and $D_{3 h}$, for which the longitudinal effect is also forbidden. In the case under study $G=\overline{6}$ and the sole polar direction is simply not in the group. Nevertheless, the transverse TPE exists in both cases. It is significant that the availability of the sole polar direction is not needed in the cut plane in all instances of the transverse TPE manifestation associated with the symmetry axis 3 . On the contrary, there is angle dependence of the effect proportional to $\cos \left(\varphi+\varphi_{o}\right)$. In such a manner the invariance condition of the polarization spatial distribution under transformations of the group $G$ is fulfilled in all cases discussed and for all possible polarization distributions.

Cases considered do not exhaust all the collection of the crystallographic cuts useful for a practical application. Really, in connection with a formulation of the problem (cuts in question are common to both heating types: radial and thickness gradient of temperature) the cuts being active with respect to TPE manifestation in the plate heated region have been investigated. However, the information reading in transmission-type power pyroelectric sensors (wavelength of a measurable radiation lies in the transparency band of the sensor element) is carried out through the use of the metal electrode system deposited on nonirradiated sections of the plate surface. Electric potential on these sections in accordance with their spatial location 
and also polar state character is generated by both heated and cold plate regions. Consequently, the use of the cuts, which are active relative to TPE appearance only in the nonheated region, is quite allowable.

\section{Conclusion}

In this paper we suggested a symmetry analysis of induced polar states in thin crystal plates subjected to axisymmetric heating by a radiation sine-modulated flux with a wavelength in the transparency band of the crystal. Crystallographic cuts being active relative to the tertiary pyroelectric effect are established in all piezoelectric classes. The presented symmetry approach proves to be an effective method for revealing principal peculiarities of the electric potential spatial distribution determining design features of IR sensors. Among physical effects which involve the polarization response to inhomogeneous heating, TPE is the most promising for practical applications.

\section{References}

1. Kosorotov V.F., Kremenchugskij L.S., Levash L.V., Shchedrina L.V. Tertiary pyroelectric effect in lithium niobate and lithium tantalate crystals. // Ferroelectrics, 1986, vol. 70 , No. $1 / 2$, p. 27-37.

2. Kosorotov V.F., Kremenchugskij L.S., Levash L.V., Shchedrina L.V. Some specific features in the behavior of dynamic pyroelectric effect under temperature gradient conditions. // Ferroelectrics, 1991, vol. 118, No. 1/4, p. 233-240.

3. Wang X.S., Zhang J.Q. A discussion on type II pyroelectric detectors. // Infrared Phys., 1992, vol. 33, No. 6, p. 475-480.

4. Pereverzeva L.P., PoplavkoYu. M., Prokopenko Y.V., Chepilko A.G. Pyroelectricity in noncentral crystals. // Acta Physica Polonica A, 1993, vol. 84, No. 2, p. 287-291.

5. Wang X.S. Tertiary pyroelectric effect on thick ferroelectric crystal plates with partially uniform heating.// Ferroelectrics Lett. Sec., 1993, vol. 15, No. 5-6, p. 159-165.

6. Kosorotov V.F., Levash L.V., Shchedrina L.V. et al. Power sensors, based on the tertiary pyroelectric effect, combined with exit windows of $\mathrm{CO}$ and $\mathrm{CO}_{2}$ lasers. // Quantum Electronics, 1994, vol. 24, No. 6, p. 543-545.

7. Kosorotov V.F., Kremenchugskij L.S., Levash L.V., Shchedrina L.V. Dynamic tertiary pyroelectric effect and its inertial properties. // Ferroelectrics, 1994, vol. 160, No. 3/4, p. $125-136$.

8. Munshi T.K., Kundu K.K., Mahalanabis R.K. Mechanical response in an N-electrode piezo-quartz bar under electrical and thermal excitations. // Acta Physica Polonica A, 1995, vol. 87, No. 6, p. 995-1002.

9. Blonsky I.V., Kosorotov V.F., Levash L.V., Shchedrina L.V. New pyroactive structure for infrared optoelectronics. // SPIE, 1999, vol. 3890.

10. Kosorotov V.F., Kremenchugskij L.S., Samoilov V.B., Shchedrina L.V. Pyroelectric Effect and Its Practical Applications, Kiev, Naukova Dumka, 1987 (in Russian).

11. Nye J.F. Physical Properties of Crystals. Their Representation by Tensors and Matrices. Oxford University Press, London, 1957. 
12. Kosorotov V.F., Kremenchugskij L.S., Shchedrina L.V. Tertiary pyroelectric effect and its application for registration of the pulse radiation. - In: Proc. of Conf. on Production and Employment of Ferro- and Piezomaterials. Moscow, 1984, p. 71-75 (in Russian).

13. Kosorotov V.F. Symmetry properties of tertiary pyroelectric effect in inhomogeneous one-dimensional temperature fields. // Inorganic Materials, 1995, vol. 31, No. 6, p. 827-830 (in Russian).

\title{
Симетрія полярних станів, індукованих неоднорідним нагрівом нецентросиметричних кристалів
}

\author{
В.П.Косоротов, Л.В.Щедріна
}

Інститут фізики НАН України, 252650 Київ, просп. Науки, 46

Отримано 17 квітня 2000 р.

В роботі запропоновано використання зовнішньої векторної дії у вигляді просторово неоднорідного нагріву кристала як оригінального і перспективного методу створення нових фізичних властивостей у традиційних кристалах, якими вони не володіють в термодинамічно рівноважному стані. Цей метод розглядається як альтернатива до загально прийнятого підходу - синтезу нових функціональних матеріалів. Зміна природи зовнішньої дії або її напрямку дає можливість керувати і варіювати поляризаційними властивостями кристалів у досить широких межах. Досліджується третинний піроелектричний ефект, який можна вважати найбільш перспективним для неперервного контролю інтенсивного 14 випромінювання.

Ключові слова: полярний стан, третинний піроелектричний ефект, симетрія

PACS: $77.60,77.70$ 
